\title{
Surgical mesh migration with Rutkow-Robbins technique causing appendicitis: A case report
}

\author{
Guadalupe K. Peña-Portillo*, Irving Amaro-Zárate, Samuel R. Medina-Parra, Juan M. Sidar-Reyes, and \\ Delfino H. Pérez-Cervantes \\ Department of General Surgery, Puebla University Hospital, Puebla, Mexico
}

\begin{abstract}
Inguinal hernias are a relatively common problem in the general population. Its repair has been a challenge in general surgery history due to complications associated with the surgical technique and the use of prosthetic mesh, including migration. An 87-year-old male patient presented with an apparent acute appendicitis. However, during surgery, a migrated mesh was found eroding the cecal appendix. The Rutkow and Robbins technique has been associated with complications, including migrated mesh, with appendicitis being one of the least described conditions associated therewith. More serial studies are necessary to prove its usefulness.
\end{abstract}

Key words: Surgical mesh. Hernia. Migration. Appendicitis.

\section{Introduction}

Appendicitis is the inflammation of the vermiform appendix and represents the most common cause of acute and emergency abdominal surgery in the world'.

Inguinal hernias represent the most frequent cause of abdominal wall defect. Nearly $75 \%$ of hernias occur in this region. Their incidence is approximately $15 / 1000$ inhabitants; the lifetime risk of developing inguinal hernias is $27 \%$ for men and $3 \%$ for women².

The use of mesh in inguinal hernia repair carries the risk of delayed rejection, migration, or foreign body-related infectious complications ${ }^{3}$.

The case of an 87-year-old male is presented here, who was diagnosed with acute appendicitis, probably complicated, and during exploratory laparotomy, a migrated prosthetic mesh was found, causing the appendicular condition, as a complication of a previous inguinal hernia surgery.

\section{Case study}

An 87-year-old male patient with a history of right inguinal hernia surgery that took place in 2012. He presented with a 4-day history of symptoms previously treated with antibiotics and non-steroidal anti-inflammatory drugs, diagnosed with urinary tract infection, with no improvement.

Physical examination revealed tachycardia, flat abdomen with absent peristalsis, with voluntary muscular resistance, depressible, McBurney's point and Rovsing's sign present, mild pain on palpation in the right flank, well localized, with no evidence of peritoneal irritation.

Laboratory studies were performed and found to be within normal parameters. In addition, a simple computed tomography scan of the abdomen showing an image corresponding to an enlarged appendix, free fluid, and plastron (Fig. 1). A diagnosis of acute appendicitis modified by medication was established and surgical intervention was elected

\section{Correspondence:}

*Guadalupe K. Peña-Portillo E-mail: gkpp16@gmail.com DOI: 10.24875/HGMX.21000006 CC BY-NC-ND license (http://creativecommons.org/licenses/by-nc-nd/4.0/).
Available online: 18-10-2021 Rev Med Hosp Gen Mex. 2021;84(4):174-176 www.hospitalgeneral.mx 


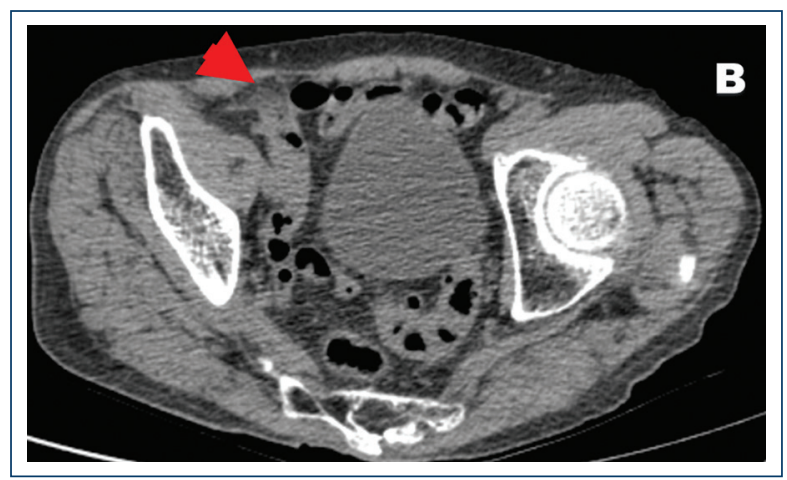

Figure 1. Computed tomography scan of the abdomen in cross-section showing the mesh eroding the parietal peritoneum, interpreted as a plastron (red arrow). No cecal appendix is identified.

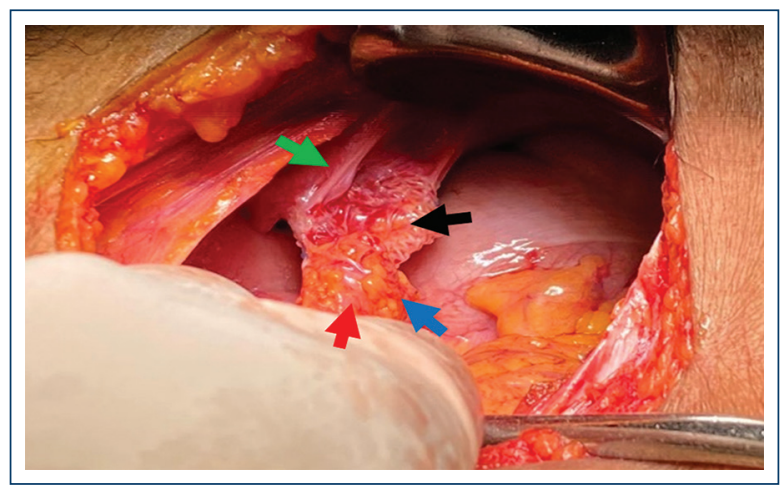

Figure 2. Surgical mesh (black arrow) eroding parietal peritoneum (green arrow), cecal appendix (red arrow), and mesoappendix (blue arrow).

Exploratory laparotomy was performed, finding coneshaped surgical mesh eroding the parietal peritoneum, with adhesions to the omentum, cecum, and cecal appendix (Fig. 2). A $10 \times 1 \mathrm{~cm}$ erythematous, edematous, and hyperemic cecal appendix, with the presence of appendicolith at the tip. Finally, an appendectomy was performed by dismantling the surgical mesh cone and closure of the peritoneum. The mesh was placed using the Lichtenstein technique in its entirety. The patient evolved favorably and was discharged $24 \mathrm{~h}$ after surgery. Pathology revealed cecal appendix with reactive lymphatic hyperplasia and passive congestion (Figs. 3-5).

\section{Discussion}

Inguinal hernia repair remains a challenge for the surgeon due to the frequency of complications, which occur in all techniques described so far. They range

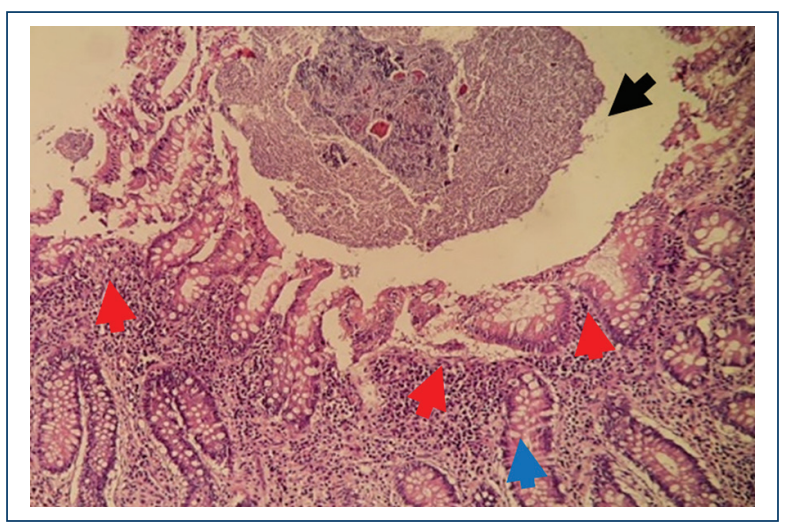

Figure 3. Histological section of pathology specimen. Appendiceal lumen (black arrow), goblet cells (blue arrow), and inflammatory reaction (red arrows).

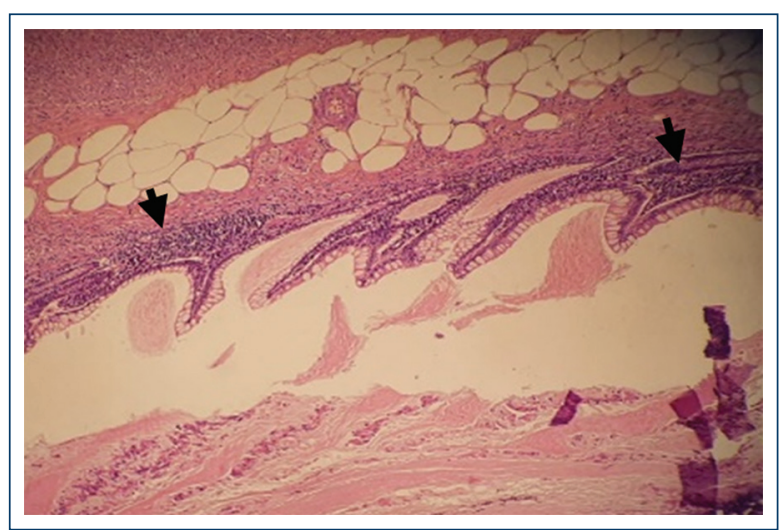

Figure 4. Lymphatic hyperplasia (black arrows).

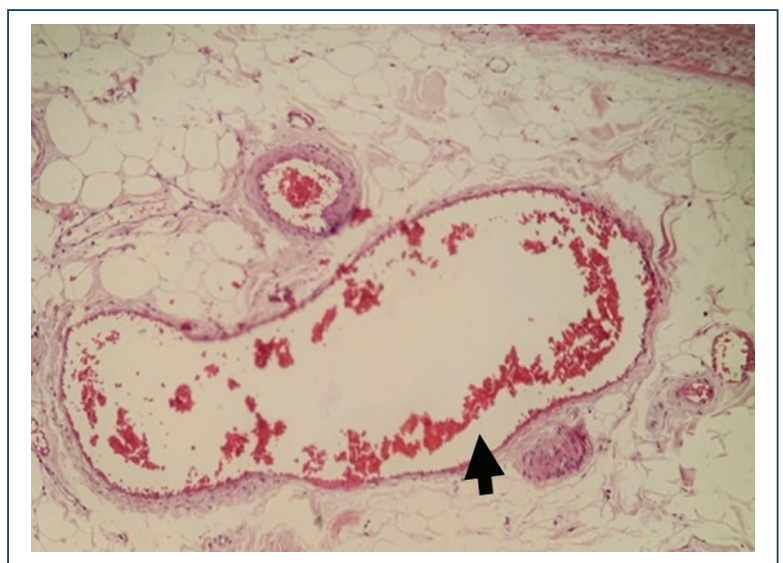

Figure 5. Vascular congestion (black arrow).

from pain at the incision site to migration with bowel occlusion ${ }^{4,5}$. Although the patient was unaware of the technique used in the previous inguinal hernia surgery, 
the finding of a cone-shaped mesh suggested a Rutkow and Robbins technique.

The Rutkow and Robbins technique for the repair of inguinal hernias was introduced in 1989 by these authors, based on the Gilbert technique. From 1989 to 2003, they performed this technique in 4404 patients, of whom $<1 \%$ presented recurrence, with a notable decrease in postoperative complications and early return to work ${ }^{6}$. Some studies report similarities with the classic Lichtenstein technique in terms of immediate and intermediate post-operative results ${ }^{7}$. However, relevant complications associated with mesh migration regarding the Rutkow and Robbins technique have been reported, such as chronic pain, bowel occlusion, intraperitoneal meshes, and adhesion to intraperitoneal structures such as the iliac vein, deep vein thrombosis due to fibrosis around the vessel, recurrence with migration to the scrotum, and small bowel fistula., ${ }^{4,5,8-11}$.

Mesh migration can be divided into primary and secondary migration. Primary migration consists of mesh movement over pathways of least resistance into contiguous anatomical spaces, due to either inadequate mesh fixation or external forces. Secondary mesh migration consists of slow, gradual movements of the mesh across trans-anatomic planes and is secondary to erosion induced by foreign body reaction. This depends on the nature of the mesh biomaterial and the type of fixation. Thus, the mesh may initially be displaced and subsequently erode adjacent tissue ${ }^{4,11}$.

Since the anatomopathological findings do not coincide with the time of evolution of the clinical condition, it can be assumed that the symptoms were secondary to the erosion of the cecal appendix by the migrated mesh, with subsequent histological changes, thus being a primary type of migration.

The relevance of this clinical case lies in the infrequency of this complication, as there are a limited number of similar cases reported in the literature. Visceral complications associated with mesh migration are considered rare and their publication occurs only as a case report. Some authors consider that these complications are not so uncommon and represent only the tip of the iceberg, both in open and laparoscopic surgeries. Hence, it is difficult to define which technique is most associated with these complications ${ }^{4}$.

In 2019, Gossetti et al. conducted a literature review of case reports of visceral complications associated with mesh migration, finding in 97 cases that the highest incidence was related to laparoscopic repair, and the lowest to the Lichtenstein technique ${ }^{4}$.
Further serial studies on long-term complications associated with this technique are needed to determine its true usefulness and develop modifications to reduce their incidence, as there are still insufficient literature and reported statistics.

\section{Acknowledgments}

We thank the staff of the Puebla University Hospital who made this work possible.

\section{Funding}

This work does not have funding of any kind.

\section{Conflicts of interest}

This work has no conflicts of interest.

\section{Ethical disclosures}

Protection of human and animal subjects. The authors declare that no experiments were performed on humans or animals for this study.

Confidentiality of data. The authors declare that they have followed the protocols of their work center on the publication of patient data.

Right to privacy and informed consent. The authors have obtained the written informed consent of the patients or subjects mentioned in the article. The corresponding author is in possession of this document.

\section{References}

1. Hernández J, De León JL, Martínez MS, Guzmán JD, Palomeque A, Cruz N, et al. Apendicitis aguda: revisión de la literatura. Cirug Gen. 2019;41:33-8.

2. Narda $L$, Camacho MR. Tipo de hernia inguinal encontrado en la población general, según la clasificación de Nyhus. Cirug Gen. 2018;40:250-4

3. Moreno-Egea A, Latorre AM. Reacción a cuerpo extraño tras reparación de hernia inguinal y alteración autoinmune tipo esclerodermia. Rev Hisp Am Hernia. 2018;1:1-2.

4. Gossetti F, D'Amore L, Annesi E, Bruzzone P, Bambi L, Grimaldi MR, et al. Mesh-related visceral complications following inguinal hernia repair: an emerging topic. Hernia. 2019;23:699-708.

5. D'Amore L, Gossetti F, Vermeil V, Negro P. Long-term discomfort after plug and patch hernioplasty. Hernia. 2008;12:445-6.

6. Luque AS, Urdaneta JR. Técnica de Rutkow y Robbins (tapón y parche) para la reparación de hernias inguinales. Hospital Dr. Manuel Noriega Trigo IVSS San Francisco, Estado Zulia, Venezuela. Colomb Med. 2009;40:300-6.

7. Ranjit-Singh R, Kumar-Gupta A, Singh-Shah A, Singh R, Singh A. A study about inguinal hernia mesh repairs: plug and patch versus Lichtenstein mesh repair technique. Int Surg J. 2016:3:1967-74.

8. Sekiguchi K, Mizuguchi Y, Mamada Y, Koizumi M, Uchida E. Intraperitoneal migration of a mesh plug from hernioplasty forming a colocutaneous fistula with the cecum: report of a case. J Nippon Med Sch. 2015;82:246-9.

9. LeBlanc KA. Complications associated with the plug-and-patch method of inguinal herniorraphy. Hernia. 2001;5:135-8.

10. Ishikawa S, Kawano T, Karashima R, Arita T, Yagi Y, Hirota M. A case of mesh plug migration into the bladder 5 years after hernia repair. Surgical Case Reports. 2015;1:4.

11. Agrawal A, Avill R. Mesh migration following repair of inguinal hernia: a case report and review of the literature. Hernia. 2006;10:79-82. 